\title{
Identification of Ethyl and $t$-Butyl Glyceryl Ethers Using Gas Chromatography Coupled with Mass Spectrometry
}

\author{
Paula M. Veiga, Cláudia O. Veloso, Ayres G. Dias and Cristiane A. Henriques*
}

\author{
Instituto de Química, Universidade do Estado do Rio de Janeiro, 20550-900 Rio de Janeiro-RJ, Brazil
}

\begin{abstract}
The ethers produced through the etherification reaction of glycerol with ethanol or $t$-butanol are used as oxygenated fuel additives, intermediates in the pharmaceutical industry, and non-ionic surfactants. However, the identification of these ethers has not been accurately done, because only some mass spectra of these compounds are available in the libraries. Moreover, there is a lack of discussion on their identification in the literature. In this work, a detailed identification of all ethers produced in the etherification of glycerol with ethanol or $t$-butanol was performed considering the mass spectra of isolated products and the comparison of the retention times. The elution order of the products was: tri-alkyl, 1,3-dialkyl, 2,3-dialkyl, 3-monoalkyl and 2-monoalkyl. In all mass spectra of the ethyl ethers, the base peak was $m / z$ 61, while in the case of $t$-butyl ethers it was $m / z 57$.
\end{abstract}

Keywords: glycerol, ether, GC-MS identification

\section{Introduction}

The use of biomass has been largely studied due to environmental issues. Platform molecules, that is, building blocks for several other chemicals are obtained from biomass by chemical and/or enzymatic processes. Some of these compounds such as polyols are highly oxygenated and can be used as precursors for chemicals and fine chemicals. Among the platform molecules, glycerol deserves to be highlighted. ${ }^{1,2}$ The conversion of glycerol into value-added products is an alternative for its disposal and surplus problems due to biodiesel production. One possibility to add value to glycerol is through the etherification reaction. The produced ethers are used as oxygenated fuel additives, intermediates in the pharmaceutical industry and non-ionic surfactants. ${ }^{3}$

The direct etherification of glycerol with alcohols or alkenes, especially with $t$-butanol or isobutene, has been widely investigated. ${ }^{4-12}$ The $t$-butyl ethers of glycerol are used as additives for fuels because of their low viscosity. The di-tert-butyl and tri-tert-butyl ethers of glycerol can be mixed directly with diesel or biodiesel. In addition, they can replace methyl-tert-butyl ether, formerly used as an additive for gasoline, but for environmental and economic reasons, its use has been reduced. The mono-tert-butyl ethers of glycerol are involved in a subsequent process

*e-mail: cah@uerj.br for the production of compounds with oxane and oxolane rings with high octane number, and are therefore useful for blending with gasoline. ${ }^{8,9}$ Depending on the etherification degree, it is possible to obtain up to five products, that is, two isomeric monosubstituted ethers (3-tert-butoxy-propane1,2-diol and 2-tert-butoxy-propane-1,3-diol), two isomeric disubstituted ethers (2,3-di-tert-butoxy-propan-1-ol and 1,3-di-tert-butoxy-propan-2-ol), and one trisubstituted ether (1,2,3-tri-tert-butoxy propane) and water.

The etherification of glycerol and ethanol to produce monoalkyl glyceryl ethers is less studied. ${ }^{13-16}$ The monoalkyl glyceryl ethers obtained from ethanol are intermediates to produce dioxolanes that can be used as co-fuels for diesel. It is important to highlight that ethanol is a green choice since it can be produced through biomass fermentation. Other five different ethers can be formed in the etherification reaction of glycerol with ethanol: two monosubstituted ethers (3-ethoxy-propane-1,2-diol and 2-ethoxy-propane-1,3-diol), two disubstituted ethers (1,3-diethoxy-propan-2-ol and 2,3-diethoxy-propan-1-ol) and also a trisubstituted ether (1,2,3-triethoxy-propane), along with water and diethyl ether.

Although the etherification reaction of glycerol and ethanol or $t$-butanol has already been studied, the identification of the products was not clearly reported. ${ }^{14,17,18}$ Moreover, the mass spectra of some products are not available in known databases and the structural similarity of the $O$-alkylated products hampers their unambiguous 
identification. So, in this work, all ethers produced in the etherification reaction of glycerol and ethanol or $t$-butanol were identified considering the mass spectra of products isolated by gas chromatography and identified by mass spectrometry, and the comparison of the retention time $\left(\mathrm{t}_{\mathrm{R}}\right)$ of known compounds.

\section{Experimental}

\section{Reaction conditions}

The etherification of glycerol with $t$-butanol or ethanol was performed in a $50 \mathrm{~mL}$ Parr reactor equipped with temperature, pressure and stirring control. Before use, the catalysts were submitted to an $e x$ situ heat treatment under $\mathrm{N}_{2}$ flow at $500{ }^{\circ} \mathrm{C}$ for $3 \mathrm{~h}$. After that, it was quickly added to the reactor containing glycerol and $t$-butanol or ethanol. The system was then heated up to reaction temperature. The catalytic tests were carried out in the liquid phase, under autogenous pressure and stirring rate of $600 \mathrm{rpm}$. Experimental conditions were selected based on the literature. ${ }^{8,13}$ Tests employing $t$-butanol were performed at $90{ }^{\circ} \mathrm{C}$, using a $t$-butanol/glycerol molar ratio equal to 4 , a reaction time of $4 \mathrm{~h}$, and $7.6 \mathrm{wt} . \%$ of catalyst (dealuminated USY zeolite) concentration, defined according to glycerol amount. ${ }^{8}$ When ethanol was used, tests were performed at $200{ }^{\circ} \mathrm{C}$, using an ethanol/glycerol molar ratio equal to 9 , a reaction time of $6 \mathrm{~h}$, and $3.5 \mathrm{wt} . \%$ of catalyst (H-Beta zeolite) concentration, defined according to glycerol amount. $^{13}$

Identification of the products

After the reaction time, the reactor was cooled to room temperature and the catalyst was separated by decantation.

The obtained products were analyzed by gas chromatography coupled with mass spectrometry (GC-MS) using an Agilent 7890-5975C gas chromatograph equipped with a capillary column VF-WAXms $(30 \mathrm{~m} \times 0.32 \mathrm{~mm} \times 0.25 \mu \mathrm{m})$ and mass selective detector (Agilent 5973). The interface was kept at $250^{\circ} \mathrm{C}$. The chromatographic conditions were: $\mathrm{H}_{2}$ as carrier gas $\left(2 \mathrm{~mL} \mathrm{~min}^{-1}\right)$, injector and detector temperature: $250^{\circ} \mathrm{C}$. The column heating program was: initial temperature: $40{ }^{\circ} \mathrm{C}$ for $1 \mathrm{~min}$; final temperature: $220{ }^{\circ} \mathrm{C}$ for $3 \mathrm{~min}$; heating rate: $20^{\circ} \mathrm{C} \mathrm{min}^{-1}$.

\section{Results and Discussion}

In the etherification reaction of glycerol with ethanol or $t$-butanol up to five products can be formed. Among them, two monosubstituted ethers (1a, 1b, 4a, 4b), two disubstituted ethers $(\mathbf{2 a}, \mathbf{2 b}, \mathbf{5 a}, \mathbf{5 b})$ and also one trisubstituted ether $(\mathbf{3}, \mathbf{6})$, as can be seen in Figure 1. Water was also observed in reaction medium as well as diethyl ether when ethanol was used.

Identification of glycerol and ethanol etherification reaction products

In the etherification of glycerol with ethanol, diethyl ether (EE), ethanol (ET) and glycerol (Gly) were identified by co-injection of commercial reagents. Figure 2 illustrates a typical chromatogram of the reaction medium of glycerol and ethanol etherification. The mass spectra for each product are in Supplementary Information section (Figures S1-S5).

The chromatographic separation is related to physicochemical properties such as polarity of the species. Thus, the selective retention of sample components on stationary phase results in differentiated migrations of the<smiles>[R]OCC(O)CO</smiles>

$1 \mathrm{a}$ or $4 \mathrm{a}$<smiles>[R]OCC(O)CO</smiles>

$2 \mathrm{a}$ or $5 \mathbf{a}$<smiles>[R]OCC(O)CO[R]</smiles><smiles>[CH-]</smiles>

$$
\mathrm{R}=\text { Ethyl or t-Butyl }
$$

\section{3 or 6}

Figure 1. Products of the glycerol and ethanol or $t$-butanol etherification reaction in the presence of acid catalyst. 1a: 3-ethoxy-propane-1,2-diol; 1b: 2-ethoxy-propane-1,3-diol; 2a: 1,3-diethoxy-propan-2-ol; 2b: 2,3-diethoxy-propan-1-ol; 3: 1,2,3-triethoxy-propane; 4a: 3-tert-butoxy-propane-1,2-diol; 4b: 2-tert-butoxy-propane-1,3-diol; 5a: 1,3-di-tert-butoxy-propan-2-ol; 5b: 2,3-di-tert-butoxy-propan-1-ol; 6: 1,2,3-tri-tert-butoxy-propane. 


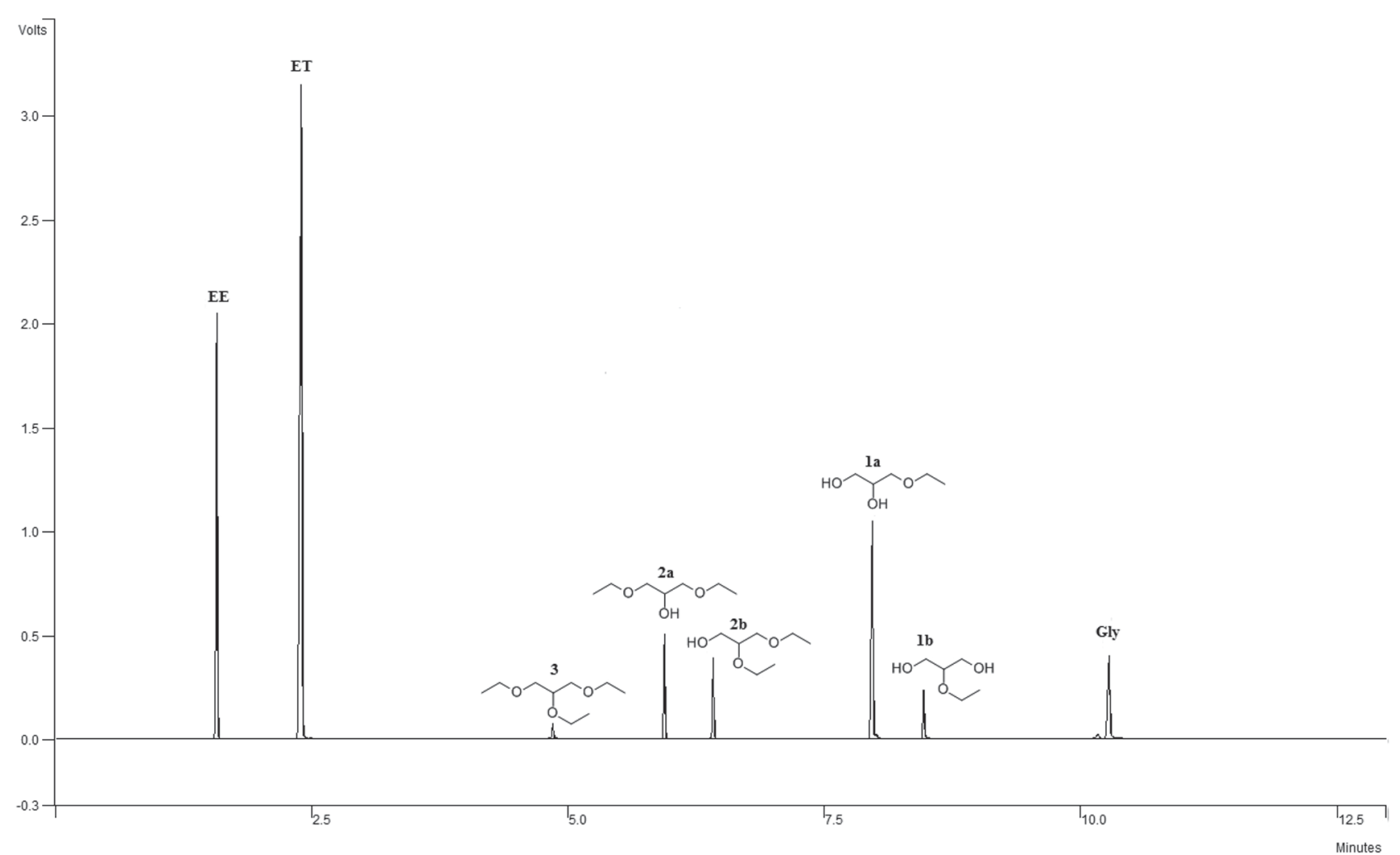

Figure 2. Chromatogram of the reaction medium of the etherification reaction of glycerol with ethanol. Peak identification: diethyl ether (EE); ethanol (ET); 1,2,3-triethoxy-propane (3); 1,3-diethoxy-propan-2-ol (2a); 2,3-diethoxy-propan-1-ol (2b); 3-ethoxy-propane-1,2-diol (1a); 2-ethoxy-propane-1,3-diol (1b); glycerol (Gly).

ethers, due to polarity difference caused by the number of hydroxyl groups in their structures. ${ }^{18}$ Thus, it is reasonable to assume that the presence of two hydroxyl groups in monoethers $(\mathbf{1 a}, \mathbf{1 b})$ promotes a strong interaction with stationary phase and, consequently, monoethers are eluted after the other ethers, that is, they have higher retention time, $\mathrm{t}_{\mathrm{R}},\left(\mathrm{t}_{\mathrm{R}}=7.9\right.$ and $8.4 \mathrm{~min}$, respectively). For disubstituted ethers (2a, 2b), the presence of only one hydroxyl group in their structures leads to a weaker interaction with stationary phase resulting in lower retention time $\left(t_{R}=5.9\right.$ and $6.4 \mathrm{~min}$, respectively) compared to monoethers. The same is true for the trisubstituted product $(3)\left(\mathrm{t}_{\mathrm{R}}=4.8 \mathrm{~min}\right)$.

To confirm the structures of these products, the comparison of the mass spectra of the etherification products with those found at mass spectroscopy database ${ }^{19}$ and the literature ${ }^{14}$ was done. However, an additional difficulty was faced since not all mass spectra of the ethers produced are in the libraries. The problem worsens due to lack of information in the literature regarding the identification of the products formed in this etherification reaction. ${ }^{13-16}$ Just one chromatogram was found for the products of glycerol and ethanol etherification. ${ }^{14}$ According to Yuan et al..$^{14}$ five peaks were observed in the retention time range shown $\left(t_{R}=4-8 \mathrm{~min}\right)$, but only four products were identified: 1,3-diethoxy-propan-2-ol, 1,2,3-triethoxy- propane, 3-ethoxy-propane-1,2-diol, an unidentified product, and glycerol, in this sequence.

The identification undergone in the present study differs from that found by Yuan et al. ${ }^{14}$ As already shown in Figure 2, eight peaks were observed. Initially, EE, ET and Gly were identified. The products 1,2,3-triethoxy-propane (3), 3-ethoxy-propane-1,2-diol (1a) and 1,3-diethoxy-propan2-ol (2a) were identified using mass spectra database. ${ }^{19}$ The other products were determined using their characteristic mass spectra and polarity, that is, monosubstituted ethers, which have two hydroxyl groups will have a higher retention time. According to product polarity, 2-ethoxypropane-1,3-diol (1b) and 2,3-diethoxy-propan-1-ol (2b) were identified. These identifications were confirmed by the analysis of the mass spectra of these compounds, as will be discussed in Figures 3 and 4. The presence of $[\mathrm{M}-18-1]^{+}$, fragment $\mathrm{m} / \mathrm{z} 129$, peak from the loss of water in $\mathbf{2 a}$ (Supplementary Information section, Figure S3) and a proeminent $[\mathrm{M}-31]^{+}$, fragment $m / z, 117$, by loss of formaldehyde in $\mathbf{2 b}$ (Supplementary Information section, Figure S4) characterize both as a secondary and primary alcohol, respectively.

The non-identified product shown by Yuan et al. ${ }^{14}$ was identified here as 2-ethoxy-propane-1,3-diol (1b), while the peak associated by the authors to 1,2,3-triethoxy-propane 
is in fact 2,3-diethoxy-propan-1-ol (2b). The trisubstituted ether was observed in a lower retention time due to the higher molecular weight and the polarity difference of the products. This result was verified through mass spectra, since the presence of the protonated molecular ion fragment $[\mathrm{M}+1]^{+}$, $\mathrm{m} / \mathrm{z} 177$ was observed (Supplementary Information section, Figure S5), confirming product identification.

The fragmentation proposals for products $\mathbf{1 a}$ and $\mathbf{1 b}$ are shown in Figure 3. The mass spectra of these products presented the ions $m / z 89$, related to the loss of $\mathrm{CH}_{3} \mathrm{O}^{+}$ from molecular ion $[\mathrm{M}-31]^{+}$and $\mathrm{m} / \mathrm{z} 61$, formed by the subsequent loss of $\mathrm{C}_{2} \mathrm{H}_{4}[\mathrm{M}-31-28]^{+}$. The latter undergoes two distinct losses of $\mathrm{H}_{2} \mathrm{O}[\mathrm{M}-31-28-18]^{+}$and $\mathrm{CH}_{2} \mathrm{O}$ $[\mathrm{M}-31-28-30]^{+}$, leading to the formation of $m / z 43$ and 31 ions, respectively (Supplementary Information section, Figures $\mathrm{S} 1$ and $\mathrm{S} 2$ ). In addition to this, a loss of $\mathrm{H}_{2} \mathrm{O}$ from molecular ion $[\mathrm{M}-18]^{+}$was also observed in 1a spectrum, leading to $\mathrm{m} / \mathrm{z} 102$ fragment. In $\mathbf{1 b}$ spectrum, $\mathrm{m} / \mathrm{z}, 72$ ion, due to hydroxyl group loss $[\mathrm{M}-31-17]^{+}$from $\mathrm{m} / z 89$ fragment, was also noted.

In the case of disubstituted ethers $(\mathbf{2 a}, \mathbf{2} \mathbf{b}), \mathrm{m} / \mathrm{z}, 129$, 102, 89, 61 ions were observed (Figure 4). The $\mathrm{m} / \mathrm{z}, 149$ ion refers to molecular ion in its protonated form and the other fragments follow the same fragmentation pattern as that for monosubstituted products, $\mathbf{1 a}$ and $\mathbf{1 b}$ (Figure 3). In addition, in the mass spectra of $\mathbf{2 a}$, the $\mathrm{m} / \mathrm{z}, 129$ ion, relative to $\mathrm{H}_{2} \mathrm{O}$ loss $[\mathrm{M}-18-1]^{+}$from molecular ion, loses the fragment $\mathrm{C}_{2} \mathrm{H}_{3} \mathrm{O}[\mathrm{M}-18-43]^{+}$leading to $\mathrm{m} / \mathrm{z}$ 86 ion (Supplementary Information section, Figure S3). In the same spectra, the $\mathrm{m} / \mathrm{z} 73$ ion is also formed. It is originated from a hydroxyl group loss [M $-59-17]^{+}$from $\mathrm{m} / \mathrm{z} 89$ ion, which is formed after a $\mathrm{C}_{3} \mathrm{H}_{7} \mathrm{O}$ loss $[\mathrm{M}-59]^{+}$ from molecular ion. The proposed fragmentations for the products $\mathbf{2 a}, \mathbf{2 b}$ and $\mathbf{3}$ are shown in Figure 4.
In the mass spectrum of the product 1,2,3-triethoxypropane, the presence of protonated molecular ion $[\mathrm{M}+1]^{+}$ at $\mathrm{m} / \mathrm{z} 177$ was observed (Supplementary Information section, Figure S5). Two distinct losses, yielding ions $\mathrm{m} / \mathrm{z}, 130$, due to loss of $\mathrm{C}_{2} \mathrm{H}_{6} \mathrm{O}[\mathrm{M}-46]^{+}$and $\mathrm{m} / \mathrm{z}, 117$, related to the loss of $\mathrm{C}_{3} \mathrm{H}_{7} \mathrm{O}[\mathrm{M}-59]^{+}$, were also observed. The ion $\mathrm{m} / \mathrm{z} 117$ undergoes successive losses of $\mathrm{m} / \mathrm{z}$ 28 resulting in ions $m / z, 89[\mathrm{M}-59-28]^{+}$and $\mathrm{m} / \mathrm{z}, 61$ $[\mathrm{M}-59-28-28]^{+}$. The same pattern was also observed in mono- and disubstituted products, as already mentioned.

As can be seen, the base peak $m / z 61$, corresponding to $\left[\mathrm{C}_{2} \mathrm{H}_{5} \mathrm{O}_{2}\right]^{+}$ion, was detected in all spectra. Except for product $\mathbf{1 b}$, in all other spectra the presence of the molecular ion in its protonated form $[\mathrm{M}+1]^{+}$was observed. Observing the fragmentation proposals for the other products, it was possible to identify a pattern of loss of two carbon atoms and one oxygen atom, or even the loss of fragments, in larger quantity, of species with three carbon atoms, followed by the loss of neutral fragments, typical of ethyl group $m / 228$. This loss pattern of two carbon atoms belonging to glycerol structure is a characteristic of homologous series.

\section{Identification of glycerol and $t$-butanol etherification reaction products}

Figure 5 illustrates a typical chromatogram profile for the etherification reaction of glycerol with $t$-butanol. The identification of the products was also carried out by GC-MS using also the polarity of the products. Six peaks were observed on the chromatogram. Gly and $t$-butanol (TA) were identified by co-injection of these compounds, so that, their retention times were determined. Under the experimental conditions used, the formation of 1,2,3-tri-tert-butoxy-propane was not observed. Only

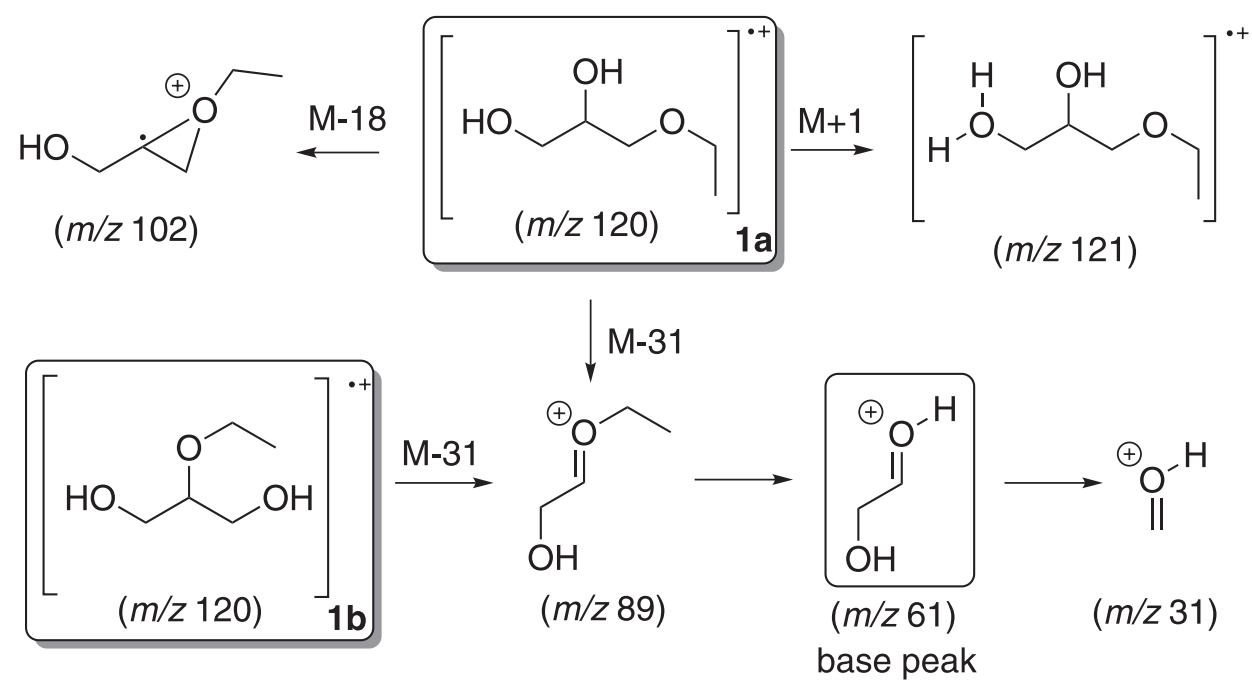

Figure 3. Proposed fragmentation pathway for $\mathbf{1 a}$ and $\mathbf{1 b}$. 


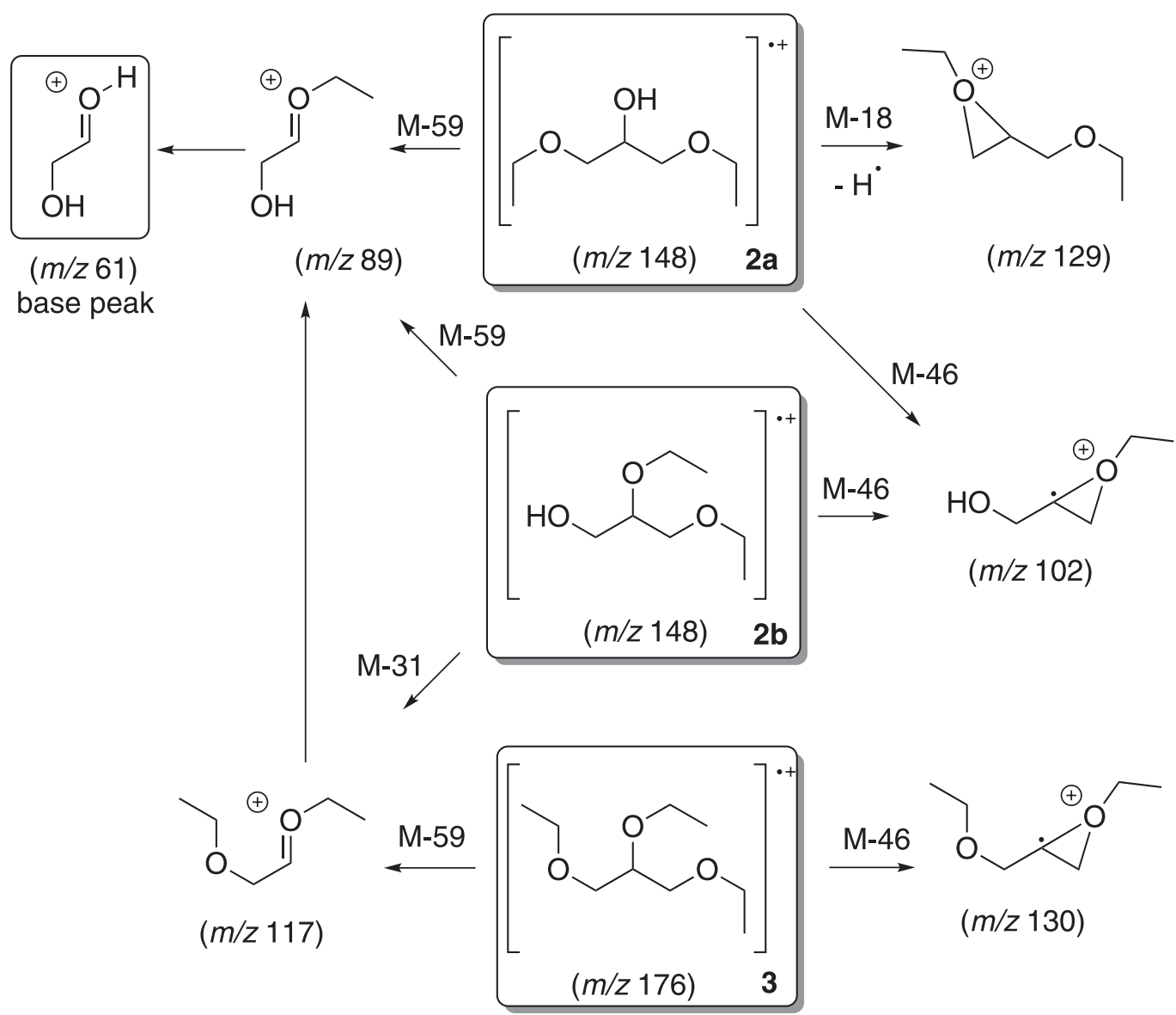

Figure 4. Proposed fragmentation pathway for diethers $\mathbf{2 a}$ and $\mathbf{2 b}$ and triether $\mathbf{3}$.

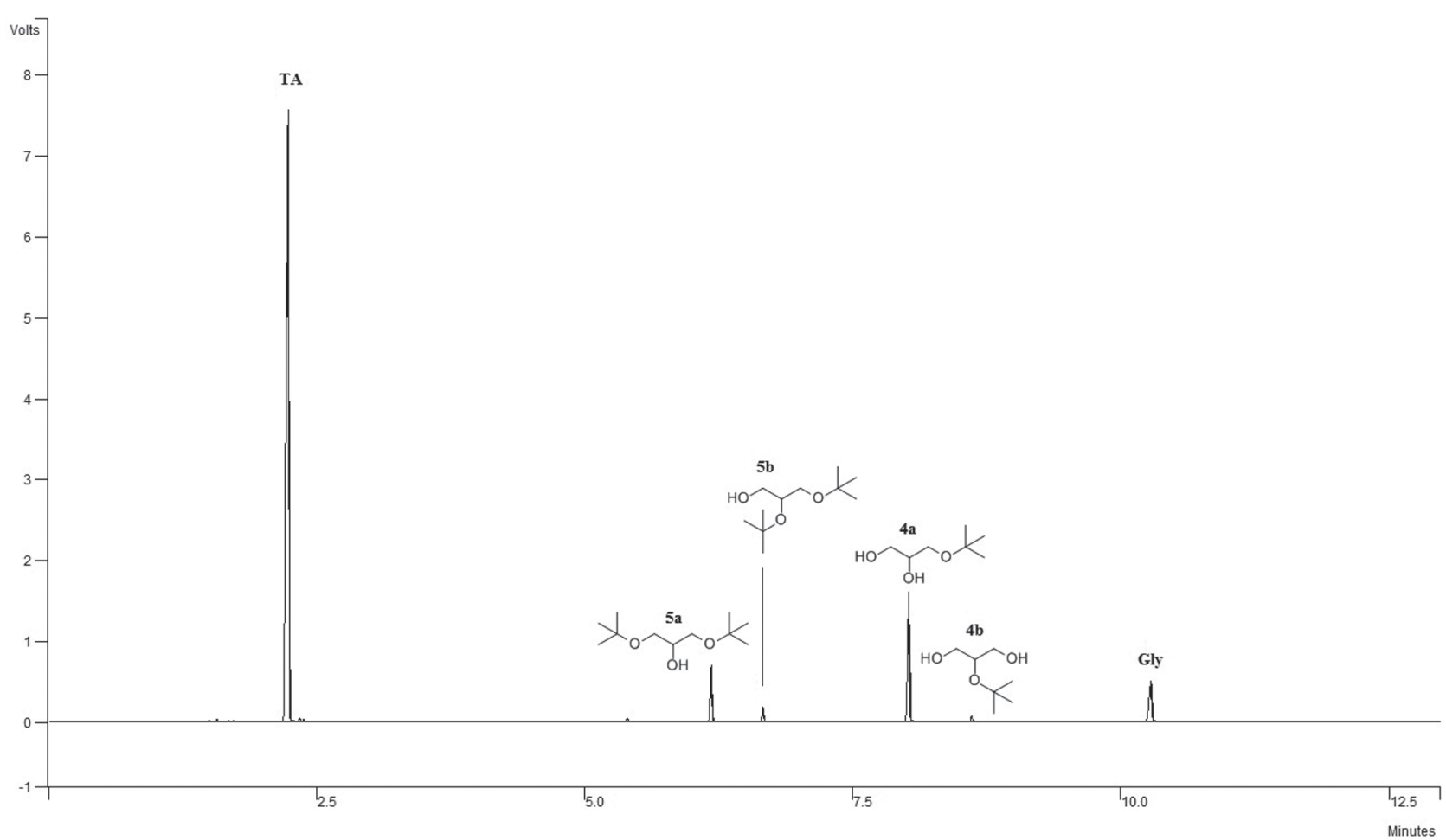

Figure 5. Chromatogram profile of the reaction medium of the etherification of glycerol with $t$-butanol. Peak identification: $t$-butanol (TA); 1,3 -di-tertbutoxy-propan-2-ol (5a); 2,3-di-tert-butoxy-propan-1-ol (5b); 3-tert-butoxy-propane-1,2-diol (4a); 2-tert-butoxy-propane-1,3-diol (4b); glycerol (Gly). 
four products were verified. As well as ethyl ethers, the retention time for $t$-butyl ethers followed the same pattern. The disubstituted ethers $(\mathbf{5 a}, \mathbf{5 b})$ had a weaker interaction with the stationary phase eluting first $\left(t_{R}=6.2\right.$ and $6.6 \mathrm{~min}$, respectively), and then the monosubstituted ethers $(\mathbf{4 a}, \mathbf{4} \mathbf{b})$ $\left(t_{R}=8.0\right.$ and 8.6, respectively). The mass spectra of these compounds are presented in Supplementary Information section (Figures S6-S9).

The patterns observed in mass spectra do not allow the distinction of glyceryl $t$-butyl ethers. The base peak at $\mathrm{m} / \mathrm{z} 57$ corresponding to fragment ion $\left[\mathrm{C}_{4} \mathrm{H}_{9}\right]^{+}$was detected in all spectra. As the mass spectra of these ethers are not available in the NIST library used ${ }^{19}$ the identification of products was based on Jamróz et al. ${ }^{17}$ and Cavalcante et al. ${ }^{18}$ The mass spectra for products $\mathbf{4 a}$ and $\mathbf{5 a}$ (major products) are identical to those observed by those authors and can be unequivocally identified. From these results and based on retention time and polarity difference of hydroxyl groups, the isomers $\mathbf{4 b}$ and $\mathbf{5 b}$ were identified. These identifications were confirmed by the obtained mass spectra.

As reported by Cavalcante et al. ${ }^{18}$ the mass spectra of monoethers (4a and $\mathbf{4 b}$ ) (Supplementary Information section, Figures S6 and S7) show ions at $\mathrm{m} / z 133$ and 117 formed from the elimination of methyl $[\mathrm{M}-15]^{+}$ and hydroxymethyl $[\mathrm{M}-31]^{+}$groups, respectively, from molecular ion. A subsequent loss of a hydroxyl group from $\mathrm{m} / z, 117$ fragment produced an ion observed at $\mathrm{m} / \mathrm{z}, 100$ $[\mathrm{M}-31-17]^{+}$. The presence of molecular ion was observed as a protonated ion $\mathrm{m} / \mathrm{z}$ 149. A proposed fragmentation for the monosubstituted ethers is shown in Figure 6.

In the spectra of disubstituted ethers (Supplementary Information section, Figures S8 and S9), the presence of molecular ion was not observed. The loss of $[\mathrm{M}-18]^{+}$and
[M - 57] due to $\mathrm{H}_{2} \mathrm{O}$ and $t$-butyl group led to $\mathrm{m} / z 186$ and 147 ions, respectively. From $m / z 147$ ion, the fragmentation pattern is the same of the monosubstituted ethers indicating that these peaks are affiliated (Figure 7). The presence of the peak $[\mathrm{M}-31]^{+}$, related to the loss of $\mathrm{CH}_{3} \mathrm{O}^{+}$, which is fundamental to identify primary alcohols was not observed probably due to the great possibility of rearrangement in $t$-butyl carbocations. So, it was not possible to distinguish the disubstituted ethers using only the spectra analysis. 1,3-di-tert-Butoxy-propan-2-ol (5a) is expected to be formed in greater amount when compared with 2,3-di-tert-butoxypropan-1-ol (5b), because of the possibility of steric hindrance of the latter. Thus, the higher relative abundance of peak 2 in Figure 5 combined with the spectra analysis allowed to identify compound $\mathbf{5 a}$ as the major isomer.

Although Cavalcante et al. ${ }^{18}$ observed the presence of nine peaks in the chromatogram presented in the publication, seven of them were duly identified. The identification presented in the present work coincides with that of the authors, but the unidentified peaks were identified in this work as 2,3-di-tert-butoxy-propan-1-ol and 2-tert-butoxy-propane-3-diol, respectively.

It is important to highlight that the characterization of alkylglycerols has received increasing attention in other science areas, ${ }^{20-22}$ since some of these ethers are considered important biological markers with a role in cell resistance and adaptation. So, considerable efforts have been made to identify them based on their mass spectra.

\section{Conclusions}

In the experimental conditions used in this work it was possible to identify all the products formed in

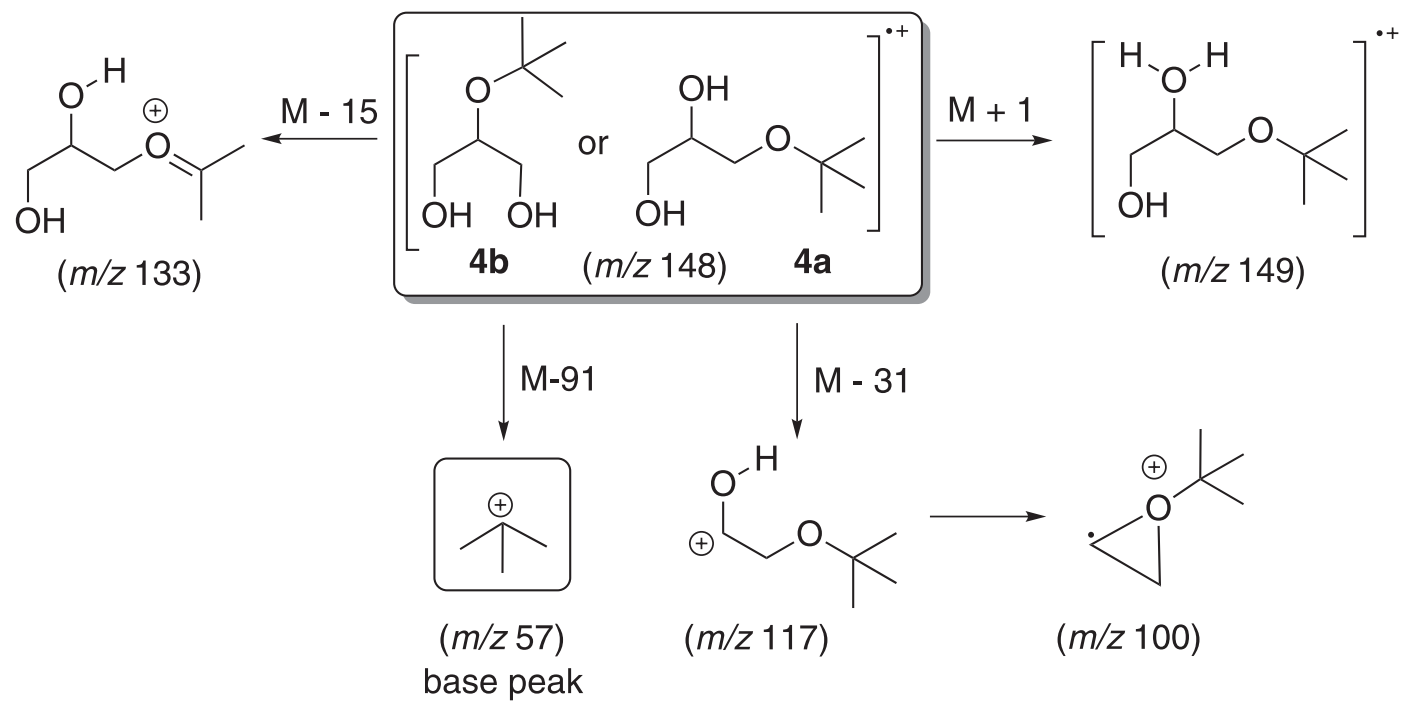

Figure 6. Proposed fragmentation pathway for monosubstituted ethers $\mathbf{4 a}$ and $\mathbf{4 b}$. 


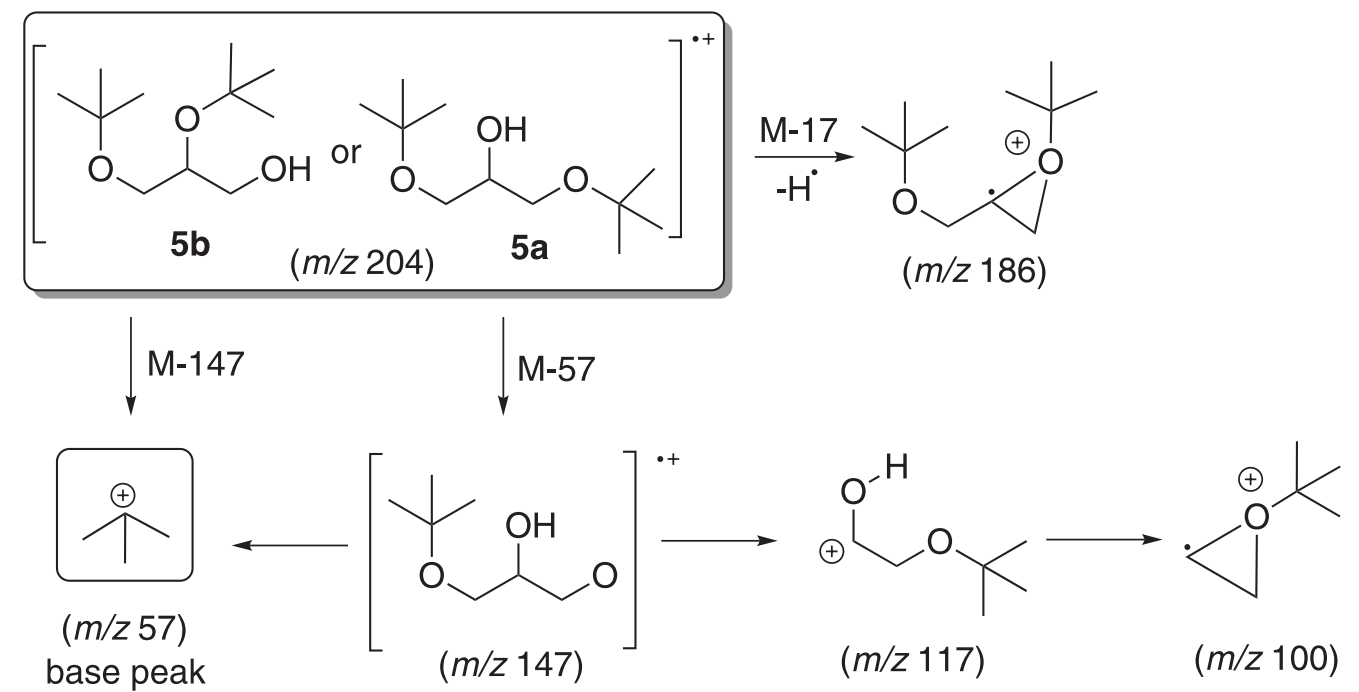

Figure 7. Proposed fragmentation pathway for disubstituted ethers $\mathbf{5 a}$ and $\mathbf{5 b}$.

the etherification reactions of glycerol with ethanol or $t$-butanol by the technique of GC-MS. Ethyl ethers have shown retention time similar to equivalent $t$-butyl ethers, following the order of elution: trialkyl; 1,3-dialkyl; 2,3-dialkyl; 3-monoalkyl and 2-monoalkyl. Fragment $[\mathrm{M}-31]^{+}$was fundamental to identify primary alcohols. Except for 2-ethoxy-propan-1,3-diol, the protoned molecular ions were observed in all mass spectra. The fragments $m / z 61$ and 57 were the base peaks for all ethyl and $t$-butyl ethers, respectively. The data set obtained for the etherification of glycerol with ethanol or $t$-butanol covers the analytical gap in the literature and corrects small imperfections allowing the GC-MS technique to be employed unambiguosly in the identification of these important products.

\section{Supplementary Information}

Supplementary information (mass spectra of ethers produced by glycerol etherification with ethanol or $t$-butanol) is available free of charge at http://jbcs.sbq.org.br as a PDF file.

\section{Acknowledgments}

Paula M. Veiga thanks CAPES (Coordenação de Aperfeiçoamento de Pessoal de Nível Superior) for doctoral scholarship. Cristiane A. Henriques thanks CNPq (Conselho Nacional de Desenvolvimento Científico e Tecnológico) and Prociência program (Universidade do Estado do Rio de Janeiro) for her research scholarship and financial support. The authors also thank NUCAT (Núcleo de Catálise, Universidade Federal do Rio de Janeiro) for GC-MS analyses.

\section{References}

1. Parvulescu, A. N.; Hausoul, P. J. C.; Bruijnincx, P. C. A.; Gebbink, R. J. M. K.; Weckhuysen, B. M.; Catal. Today 2010, 158, 130.

2. Ruppert, A. M.; Parvulescu, A. N.; Arias, M.; Hausoul, P. J. C.; Bruijnincx, P. C. A.; Gebbink, R. J. M. K.; Weckhuysen, B. M.; J. Catal. 2009, 268, 251.

3. Yin, Y.; Guo, X. Y.; Dai, W. L.; Fan, K. N.; Green Chem. 2009 , $11,1514$.

4. Karinen, R. S.; Krause, A. O. I.; Appl. Catal., A 2006, 306, 128.

5. Klepáčová, K.; Mravec, D.; Bajus, M.; Appl. Catal., A 2005, 294, 141.

6. Klepáčová, K.; Mravec, D.; Bajus, M.; Chem. Pap. 2006, 60, 224.

7. Klepáčová, K.; Mravec, D.; Kaszonyi, A.; Bajus, M.; Appl. Catal., A 2007, 328, 1.

8. Viswanadham, N.; Saxena, S. K.; Fuel 2013, 103, 980.

9. González, M. D.; Cesteros, Y.; Llorca, J.; Salagre, P.; J. Catal. 2012, 290, 202.

10. Srinivas, M.; Raveendra, G.; Kumar, C. R.; Prasad, P. S. S.; Lingaiah, N.; Indian J. Chem. 2014, 53, 524.

11. Manjunathan, P.; Kumar, M.; Churipard, S. R.; Sivasankaran, S.; Shanbhag, G. V.; Maradurer, S. P.; RSC Adv. 2016, 6, 82654.

12. Estevez, R.; López, M. I.; Jiménez-Sanchidrián, C.; Luna, D.; Romero-Salguero, F. J.; Bautista, F. M.; Appl. Catal., A 2016, 526, 155.

13. Pariente, S.; Tanchoux, N.; Fajula, F.; Green Chem. 2009, 11, 1256.

14. Yuan, Z.; Xia, S.; Chen, P.; Hou, Z.; Zheng, X.; Energy Fuels 2011, 25, 3186.

15. Melero, J. A.; Vicente, G.; Paniagua, M.; Morales, G.; Muñoz, P.; Bioresour. Technol. 2012, 103, 142.

16. Pinto, B. P.; Lyra, J. T.; Nascimento, J. A. C.; Mota, C. J. A.; Fuel 2016, 168, 76. 
17. Jamróz, M. E.; Jarosz, M.; Witowska-Jarosz, J.; Bednarek, E.; Tęcza, W.; Jamróz, M. H.; Dobrowolski, J. C.; Kijeński; Spectrochim. Acta, Part A 2007, 67, 980.

18. Cavalcante, K. S. B.; de Souza, A. G.; Filho, N. R. A.; Soares, A. T.; Mendonça, S. J. R.; Maciel, A. P.; Silva, F. C.; Rev. Virtual Quim. 2014, 6, 244.

19. NIST Mass Spectral Search Program Version 2.0; National Institute of Standards and Technology: Gaithersburg, 2008.

20. Grossi, V.; Mollex, D.; Vinçon-Laugier, A.; Hakil, F.; Pacton, M.; Cravo-Laureaub, C.; Appl. Environ. Microbiol. 2015, 81, 3157.
21. Santos, V. L. C. S.; Billett, D. S. M.; Wolff, G. A.; J. Braz. Chem. Soc. 2002, 13, 653.

22. Oliveira, H. S.; Resende, J. M.; Souza, P. P.; Patrício, P. S. O.; Oliveira, L. C. A.; J. Braz. Chem. Soc. 2017, 28, 2244.

Submitted: September 11, 2017 Published online: December 14, 2017 